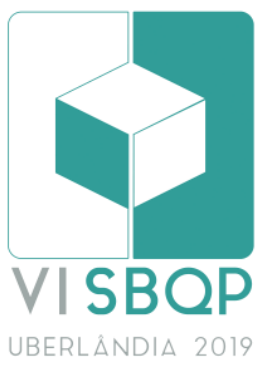

\title{
MICROAPARTAMENTOS EM EMPREENDIMENTOS IMOBILIÁRIOS CONTEMPORÂNEOS
}

\author{
PANE, Mariana Fragali \\ Instituto de Arquitetura e Urbanismo - USP, e-mail: marianapane@usp.br \\ CORBO, Carolina Sanches \\ SENAC Unidade Ribeirão Preto, e-mail: carolinasanchescorbo@gmail.com \\ PERSONA, Marcos Vinícus \\ SENAC Unidade Ribeirão Preto, e-mail: m.persona@hotmail.com \\ CARLUCCI, Marcelo \\ SENAC Unidade Ribeirão Preto, e-mail: cep_arquitetos@hotmail.com
}

\begin{abstract}
RESUMO
A redução da área útil dos apartamentos residenciais ao longo dos últimos anos tem sido um fenômeno identificado com frequência entre os agentes envolvidos na comercialização, projeto e construção dessa tipologia edilícia. Este artigo, fruto de um trabalho de conclusão do curso de especialização em Design de Interiores, busca refletir e identificar as características, causas e implicações desse fenômeno se apoiando tanto na ótica do mercado imobiliário quanto nas demandas e expectativas dos usuários. Usando a metodologia de estudo de caso, foram escolhidos como objeto de estudo dois empreendimentos residenciais: o conjunto residencial "VN Nova Higienópolis" da construtora e incorporadora Vitacon, com 10m² de área útil, e o residencial "MOOV Estação Brás" da incorporadora Gafisa, com 19m² de área útil, ambos situados na cidade de São Paulo. Nas análises feitas foram consideradas características como a metragem quadrada, dimensões mínimas, entre outros aspectos ligados ao perfil dos moradores e público-alvo desses apartamentos afim de aferir o atendimento as expectativas e necessidades do usuário. A pergunta que permeou a pesquisa foi: a redução significativa do espaço interno dos apartamentos residenciais se configura exclusivamente como estratégia de otimização do lucro em relação ao solo urbano ou atende a transformações na forma de vida e na rotina dos usuários no sentido de compartilhar determinados usos e funções e manter espaços privados que essencialmente satisfaçam necessidades básicas do cotidiano?
\end{abstract}

Palavras-chave: Microapartamentos; Ambientes Flexíveis; Dimensionamento Mínimo; Morar Contemporâneo.

\begin{abstract}
The reduction of the useful area of the residencial apartments all over the years has been a phenomenon identified in the real state market, in the project and in the construcion of this building type. This article is a result of a research performed in an interior design specialization course. This research intend to reflect and identify the features, the causes and the implications of this phenomenon based on both the real estate market and the user's demands and expectations. Using case study methodology, it was choosen two residencial developments: the residential complex "VN Nova Higienópolis" of the constructor and incorporator Vitacon, with apartment of $10 \mathrm{~m}^{2}$ of floor area, and the MOOV BRAS Station of the constructor and incorporator Gafisa, with $19 \mathrm{~m}^{2}$ of floor area, both located in the city of São Paulo. The analysis considered characteristics such as square footage, minimum dimensions, among other aspects related to the profile of the residents and target audience of these residential developments in order to assess the user's expectations and needs. Therefore, the research was based on the
\end{abstract}

PANE, M. F.; CORBO, C. S.; PERSONA, M. V.; CARLUCCl, M. Microapartamentos em empreendimentos imobiliários contemporâneos. In: SIMPÓSIO BRASILEIRO DE QUALIDADE DO PROJETO NO AMBIENTE CONSTRUÍDO, 6., 2019, Uberlândia. Anais... Uberlândia: PPGAU/FAUED/UFU, 2019. p. 333-344. DOI https://doi.org/10.14393/sbqp19032. 
following question: is the change of internal space of residential apartments associated only with the real state companies aim to increase the profit, or is it also associated with the transformation of the users routine and lifestyle, keeping as private only the areas for the basic necessities?

Keywords: Microapartments; Flexible environments; Minimum Sizing; Contemporary Living.

\section{INTRODUÇÃO}

Seja pelo alto valor do metro quadrado $\left(\mathrm{m}^{2}\right)$ ou pelo aumento populacional nos centros urbanos gerando um déficit habitacional, no decorrer dos últimos 50 anos é perceptível a diminuição do tamanho dos espaços de morar, em especial da unidade habitacional conhecida como apartamento. Como é possível observar a partir da Figura 01, os apartamentos passaram por uma trajetória de redução de espaço que se inicia na década de $70 \mathrm{com}$ uma metragem média de $100 \mathrm{~m}^{2}$ (a), passando para $87,80 \mathrm{~m}^{2}$ (b) no período de 1980 a 1990, chegando a aproximadamente $72 \mathrm{~m}^{2}$ (c) na década de 90 , até chegar aos $73 \mathrm{~m}^{2}$ (d) nos anos 2000 e aos 59,60 m² (e) no ano de 2010. Paralelamente, o espaço interior sofreu remodelações no decorrer desse período, tendo áreas extintas como o vestíbulo e o quarto da empregada, além da descompartimentação dos espaços, resultado da integração da área de serviço integrada a cozinha e a união das salas e copa em um único espaço integrado e menor.

Porém, em 2017, essa redução atingiu novos patamares com o lançamento do edifício VN Nova Higienópolis, projeto da incorporadora Vitacon na cidade de São Paulo, cujos apartamentos possuem área de $10 \mathrm{~m}^{2}$, levando o título de menor apartamento da América Latina, e inspirando outras construtoras a lançarem produtos semelhantes, os chamados microapartamentos.

A motivação de tais empreendimentos é permitir que os usuários usufruam melhor da cidade, uma vez que ficam próximos a transportes públicos, centros comerciais, parques e centros culturais. Segundo Alexandre Frankel, presidente da Vitacon, em coletiva:

Não, a intenção de Frankel não é a de "asfixiar" potenciais moradores, como se poderia pensar. "O paulista tem que usufruir o melhor da urbanidade, não pode ser escravo do trânsito e de afazeres domésticos", ressaltou ontem à coluna. (RACY, 2017)

Mas nem todos são simpáticos a essa proposta. Para Rolnik (2017) esse tipo de empreendimento é um produto com intenção de aumentar as margens de lucro das incorporadoras, uma vez que tendem a aumentar o número de unidades possíveis de venda em um único edifício. Sua crítica se deve principalmente pelo alto valor do metro quadrado dessas unidades, que chegam a aproximadamente 10 mil reais, resultando em um elevado preço de mercado. Soma-se a isso, o futuro valor mensal do condomínio, que pela quantidade de equipamentos que o empreendimento oferece aos usuários, tem tudo para ter um valor excessivo. Logo esses empreendimentos tendem a ser exclusivos para um nicho específico da sociedade, excluindo a grande maioria da população. (ROLNIK, 2017)

Visando entender melhor os microapartamentos, esse artigo tem como objetivo a análise desse produto a partir do olhar crítico do design de interiores. 


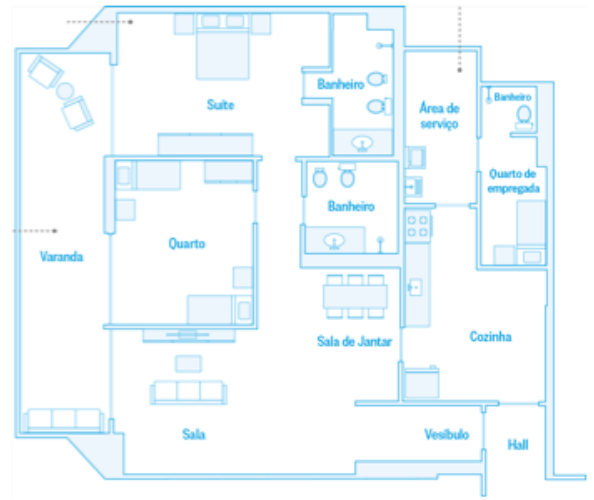

(a)

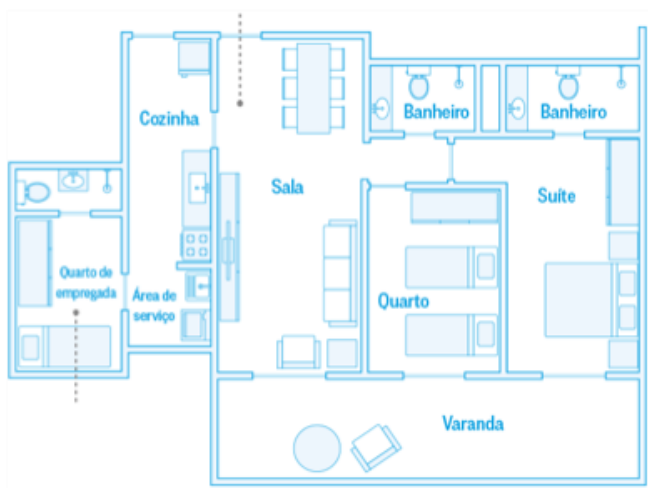

(b)

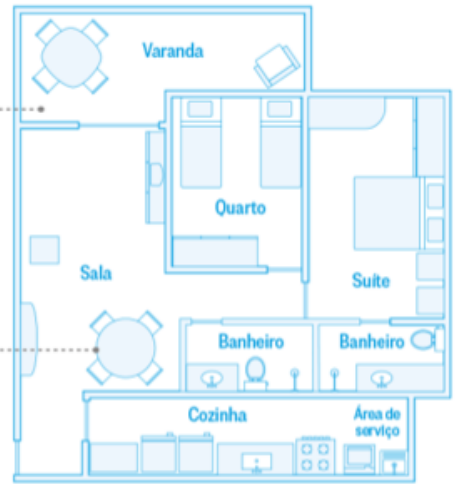

(c)

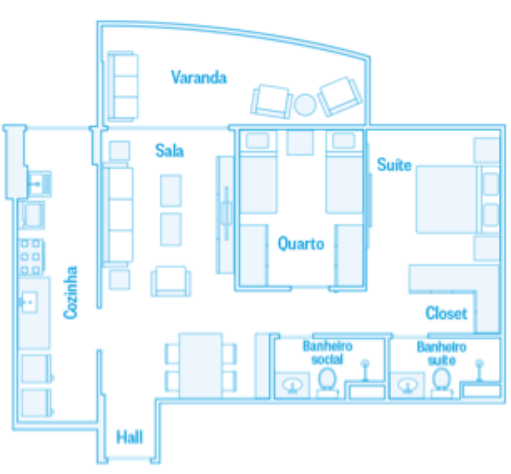

(d)

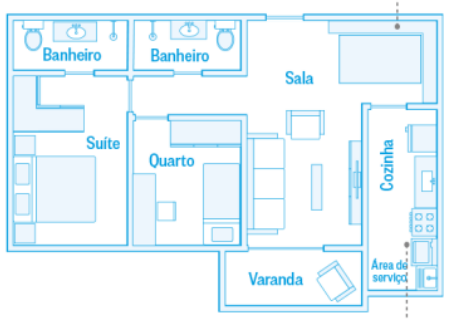

(e)

Figura 1 - Evolução de apartamentos de 1970 à 2010. (a) $100 \mathrm{~m} 2$ dos anos 70. (b) 87,80 $\mathrm{m} 2$ dos anos 80 . (c) $72,85 \mathrm{~m} 2$ dos anos 90 . (d) 73,76 m2 dos anos 2000. (e) $59,60 \mathrm{~m} 2$ dos anos 2010.

Fonte: Ademi. Disponível em: https://infograficos.oglobo.globo.com/economia/exemplos-de-plantas-deapartamentos-de-dois-quartos-ao-longo-das-decadas.html

\section{FUNDAMENTAÇÃO}

A realização desses empreendimentos e seu aceitamento pelo público se deve, principalmente, pela metamorfose comportamental do usuário e do perfil dos habitantes da cidade que vem se modificando no decorrer dos últimos anos. Tramontano (1997) já anunciava essa alteração quando diz:

[...] Mais e mais pessoas solteiras, jovens profissionais, trabalhadores de escritórios e estudantes preferem gastar maiores somas com o aluguel de um apartamento - cuja área é cada vez menor - situado nas áreas centrais das cidades, ao invés de submeterem-se a longos deslocamentos diários em transportes coletivos, vivendo em bairros e subúrbios distantes, longe da vida noturna e do lazer urbano. (TRAMONTANO, 1997)

Esse pensamento é semelhante a proposta dos membros do Archigram na década de 60. Este grupo de origem inglesa teorizava a união da habitação e cidade, propondo habitações que possuiam apenas as funções estritamente individuais e solitárias, e deixando as funções coletivas para o ambiente urbano, resultando em uma habitação mínima e supertecnológica. (TRAMONTANO, 1997).

A solução dada aos microapartamentos lançados em São Paulo é semelhante a de Kisho Kurokawa no Nakagin Capsule Tower. Construído em 1972, este exemplar do "metabolismo Japonês" é constituído por 140 cápsulas préfabricadas de $10 \mathrm{~m}^{2}$, conectadas a uma estrutura principal contendo os elementos de circulação do edifício, e equipamentos básicos de uma 
habitação, tais como cama, fogão, banheiro, entre outros. (BRITTO, 2013).

Outra similaridade entre essas unidades habitacionais é a planta livre. Esta descompartimentação dos espaços auxilia no conforto do usuário, permitindo a ventilação e iluminação de todo o apartamento pela única janela que o ambiente tem, possibilitando também a sensação de amplitude do espaço.

É necessário, porém, um bom planejamento do espaço interno desses apartamentos, de modo a aproveitar de maneira inteligente todo o espaço existente e evitar que o ambiente se torne claustrofóbico. Um exemplo de como a falta de planejamento em microapartamentos pode ser prejudicial é visto através do trabalho do fotógrafo Benny Lam (Figura 02). Em situações pouco mais extremas que os casos estudados, o fotógrafo registra as condições de vida de flats na cidade de Hong Kong, na China, onde os espaços são extremamente pequenos e o ambiente se torna asfixiante pelo uso de móveis convencionais.
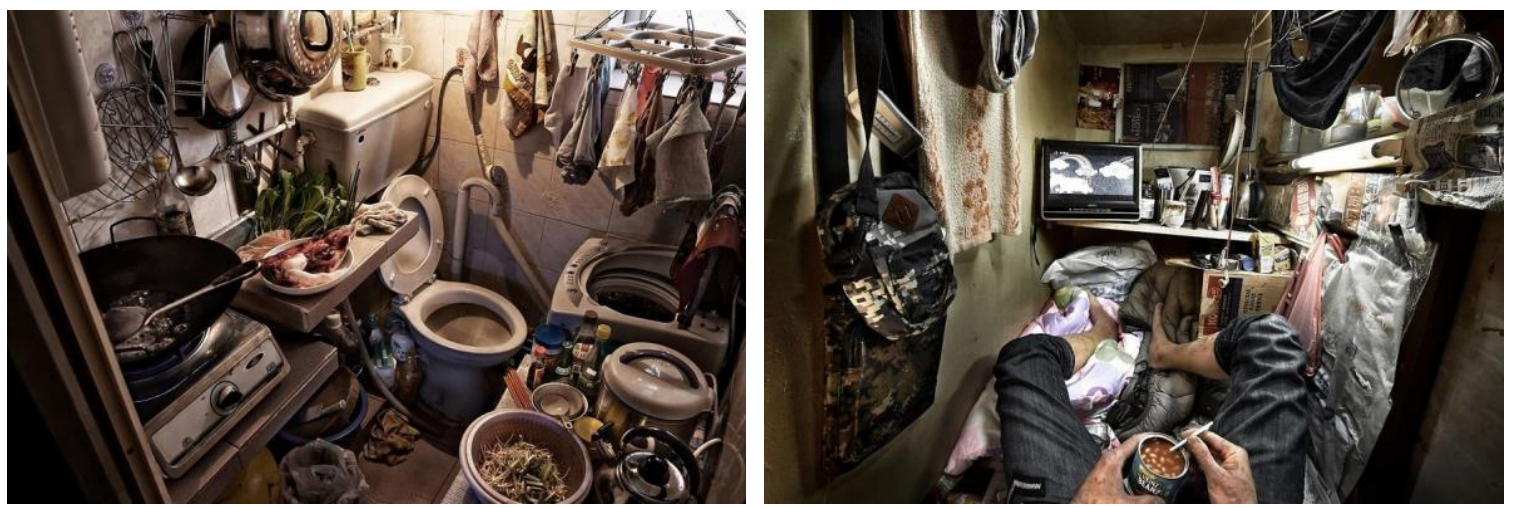

Figura 2 - Fotografias tiradas pelo fotógrafo Benny Lam, nos microapartamentos de Hong Kong, conhecidos como "cubículos caixões.

Fonte: Benny Lam. Disponível em: https://www.theguardian.com/cities/gallery/2017/jun/07/boxed-life-insidehong-kong-coffin-cubicles-cage-homes-in-pictures)

Para esses apartamentos, o ideal é que seja adotado uma revisão das propostas Modernas de Perret, Le Corbusier, Mies Van de Rohe e as desenvolvidas durante o entre guerras adotadas pela Alemanha, onde:

[...] a pouca área útil de cada unidade foi tratada com elementos flexíveis - camas escamoteáveis, mesas dobráveis ou sobre rodízios, portas de correr - procurando viabilizar a meta de um cômodo por pessoa, fosse ele minúsculo. (TRAMONTANO, 1997)

A flexibilidade como partido do ambiente e dos mobiliários que nele estarão, só tem a facilitar a vivência e o conforto do usuário, de modo que ela deve ser levada em consideração ao projetar o interior desse novo produto do mercado brasileiro, o microapartamento. Considerando ainda o avanço tecnológico obtido nos últimos anos, a possibilidade de agregar tecnologias ao mobiliário já é viavelmente possível através da automação residencial.

\section{METODOLOGIA}

Para esse estudo, foi optado a metodologia de estudo de casos, tendo como objetos de estudo os apartamentos dos edifícios VN Nova Higienópolis, com 10 $\mathrm{m}^{2}$, e MOOV Estação Brás, com $19 \mathrm{~m}^{2}$ de área, usando o processo de argumentação lógica proposto por Groat e Wang (2002), que da ordem a um conjunto de fatores previamente dispares devido a interconexões anteriores desconhecidas ou sistematização de fatos relevantes associados, utilizando 
como estratégia estudo de caso.

A escolha dos casos foi motivada pelo fato de ambos terem características semelhantes, tais como metragem quadrada mínima, compartimentação dos ambientes, localização, entre outros fatores que os colocam em um mesmo nicho comparativo.

Definido os objetos, a proposta é investigá-los de modo a analisar os mobiliários, as configurações possíveis durante diferentes situações, a flexibilidade dos ambientes e a definição do morar eventual.

Dessa maneira usamos a sistematização de fatos associados dos estudos de caso e comparamos esses fatos entre si para obter os resultados.

Para embassar esse estudo, foram feitos levantamentos bibliográficos sobre a evolução dos apartamentos no decorrer dos anos, uma análise do novo morar, a disposição dos apartamentos contemporâneos com a ausência de compartimentação dos ambientes e a flexibilidade dos ambientes e dos mobiliários.

Também um levantamento documental dos empreendimentos escolhidos como objetos de estudo, com a finalidade de uma análise minuciosa de suas particularidades. Soma-se a isso, um levantamento das plantas e imagens dos apartamentos, que vão desde imagens das áreas comuns dos edifícios, do contexto e do público consumidor.

\section{RESULTADOS E DISCUSSÕES}

\subsection{Estudo 1: VN Nova Higienópolis, São Paulo - SP}

Projetado pela Marchi Arquitetura para a construtora e incorporadora Vitacon, o empreendimento imobiliário VN Nova Higienópolis, lançado em 2017, possui apartamentos de $77 \mathrm{~m}^{2}$ a $10 \mathrm{~m}^{2}$ de área. Sendo a tipologia de 10 $\mathrm{m}^{2}$, objeto de estudo, sendo considerada o menor apartamento da América Latina.

Situado na região central da cidade de São Paulo, o empreendimento possui localização privilegiada próximo a transportes públicos, como as estações Santa Cecília e Marechal Deodoro, à aproximadamente 450 metros. O edifício também fica próximo ao hospital Santa Cecília, Hospital Samaritano e Universidade Mackenzie.

O VN Nova Higieópolis é um edificío de médio e alto padrão que diz ser ideal para jovens e casais que estão iniciando uma nova família. Porém, o contexto de sua localização possibilita ampliar e especificar seu público-alvo para além desses dois grupos citados anteriormente. Devido a sua proximidade com os hospitais citados, se abre o nicho específico de profissionais da saúde, tais como médicos e enfermeiros, que buscam um espaço próximo ao trabalho para que possam descansar entre seus plantões. O caráter dormitório do apartamento e a proximidade com a Universidade Mackenzie também visa atingir um outro público: os estudantes universitários.

Pode se dizer que, tanto os profissionais da saúde, como os estudantes e até os jovens casais, têm uma realidade em que grande parte do seu dia é vivida fora da residência, sendo esta mais um local de repouso e passagem. É o novo morar contemporâneo, de modo que o espaço restrito do apartamento não é uma grande limitação para o usuário.

Devido ao espaço restrito de $10 \mathrm{~m}^{2}$ do apartamento VN Nova Higienópolis, é 
necessário que o ambiente possua um bom design de interiores, com móveis planejados, sob medida e flexíveis, garantindo que todas as necessidades do usuário sejam atendidas. Para provar que é possível ter todas as necessidades supridas, a própria Vitacon divulgou em seu material comercial as diferentes configurações que o espaço pode abranger com a ajuda de móveis planejados e flexíveis.

Como é visto nas plantas baixas (Figura 03), o apartamento não é compartimentalizado, possuindo divisórias apenas no banheiro que por serem de vidro, ainda transmite uma sensação de unidade e amplitude. É possível observar também que a planta tem duas configurações que podem ser adotadas, uma diurna com o sofá onde o usuário pode descansar e receber visitas (a), e uma noturna onde o sofá se transforma em cama (b). Além de permitir diferentes cenas, as configurações dão exemplos de mobiliário flexível, caso do sofá que se transforma em cama (Figuras 03).

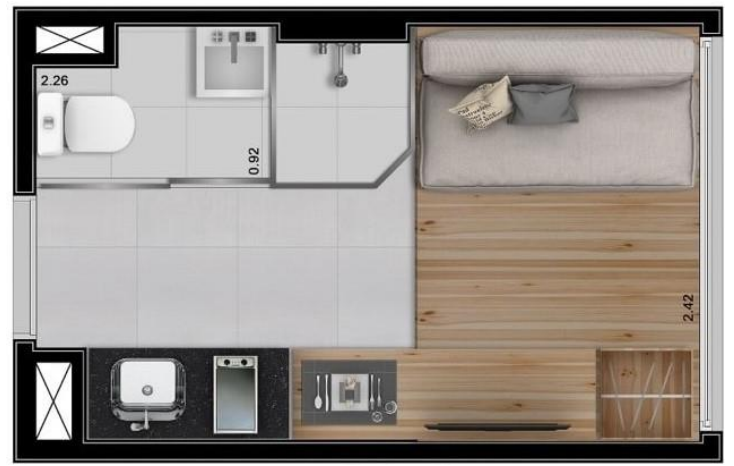

(a)

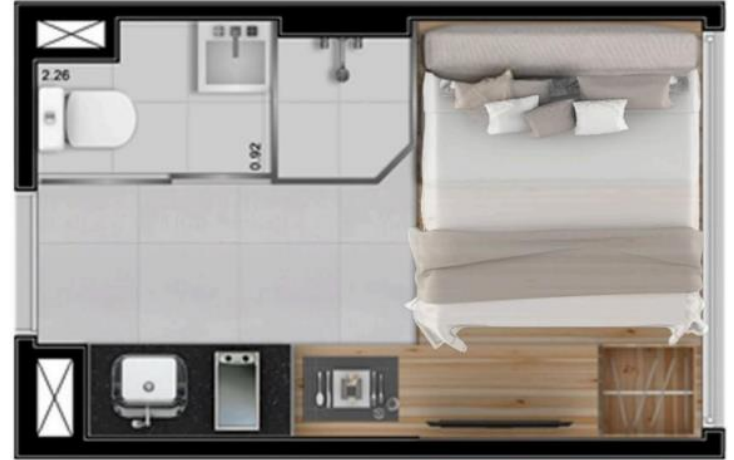

(b)

Figura 3 - Planta baixa. (a) Opção sofá. (b) Opção cama. Fonte: Site da construtora e incorporadora VITACON.

Além do sofá-cama, o vídeo apresenta outras propostas de mobiliários flexíveis e adaptados para o ambiente, aproveitamento o máximo do espaço, como é o caso da mesa de refeições que é o fundo do armário com espelho (a), mas, com seu movimento de sobe e desce, ocupa o ambiente apenas quando necessário o seu uso (b), liberando espaço nos outros momentos, além de poder ser uma mesa de passar roupa (c) (Figura 04).

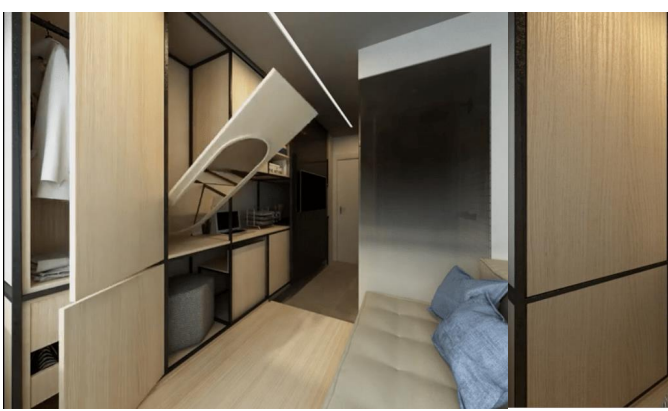

(a)

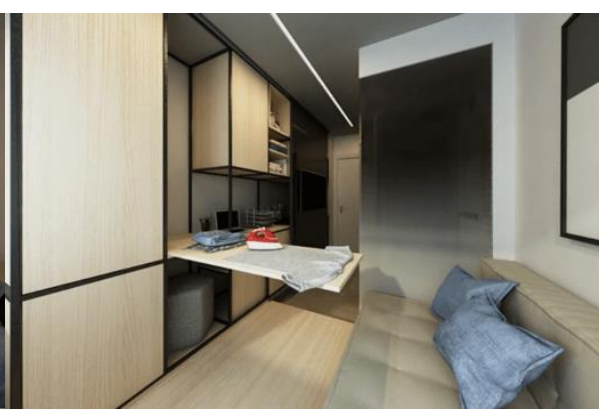

(c)

Figura 4 - (a) Fundo do armário com espelho flexível. (b) Utilizado como mesa de refeições. (c) Ou mesa de passar roupa.

Fonte: Site da construtora e incorporadora VITACON.

Outro exemplo, visto na figura 05, é a sapateira proposta em degrau (a) que ocupa um espaço horizontal, sem atravancar a passagem, funciona ainda como divisor dos ambientes sala/quarto e cozinha. Esta por sua vez, é planejada, com bancada em todo sua extensão, contendo área útil para 
preparação de alimentos, cooktop e cuba (b). Por fim o vídeo sugere a televisão fixada em uma porta de correr, que ora serve como porta do guarda-roupa (c), ora para esconder a cozinha (d).

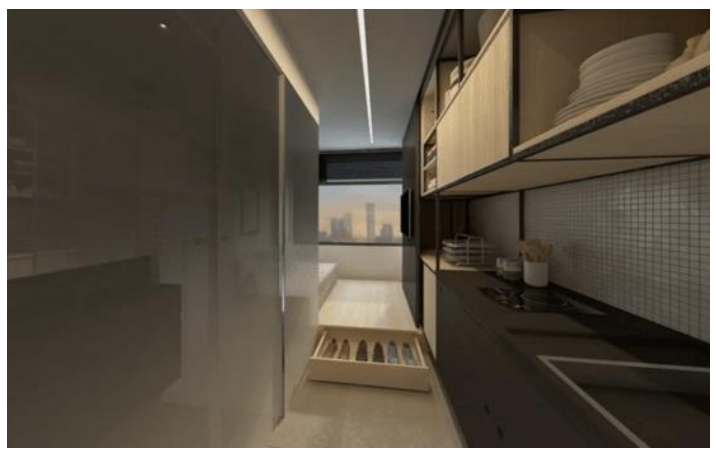

(a)

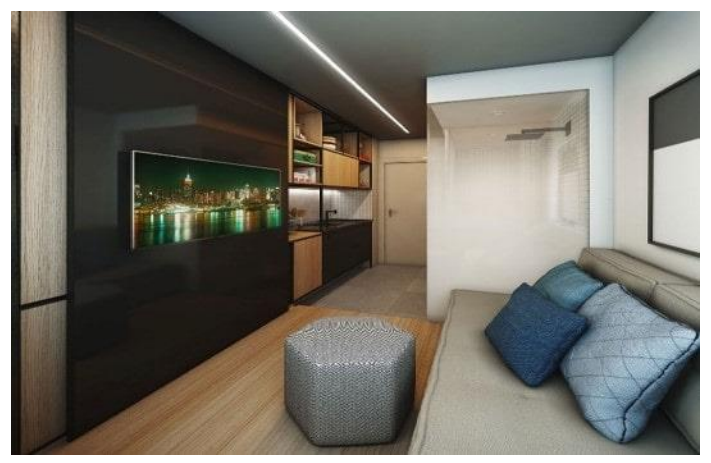

(c)

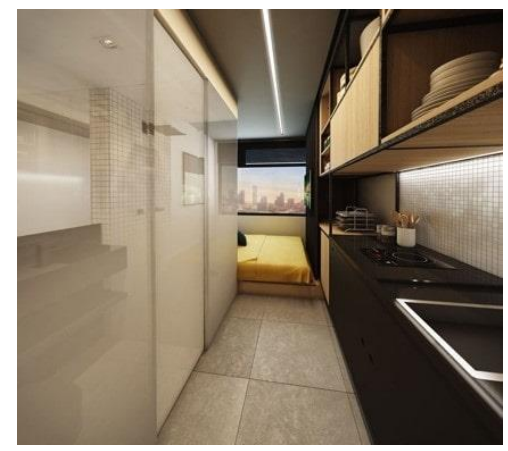

(b)

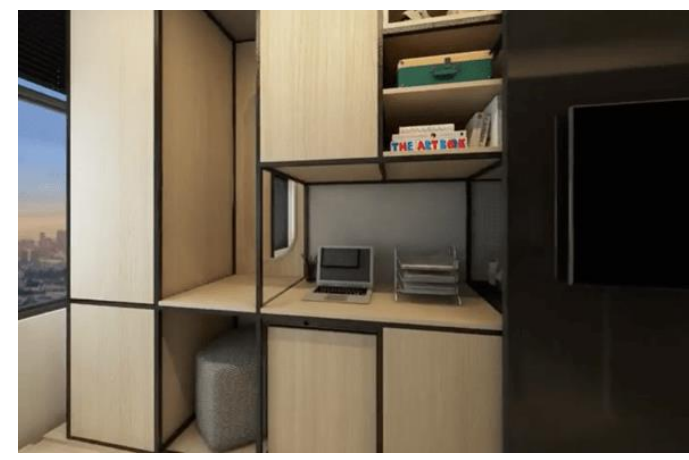

(d)

Figura 5 - (a) Sapateira embutida no tablado divisor de ambientes. (b) Bancada em toda a extensão da cozinha. (c) Painel com TV escondendo o armário e atendendo a sala. (d) Painel com TV escondendo a cozinha e expondo o armário. Fonte: Site da construtora e incorporadora VITACON.

Sendo um apartamento destinado a um público de médio e alto padrão, os acabamentos foram pensados de modo a atender esse público, contando com tomadas USB e fechadura biométrica, caracterizando o ambiente como um espaço hight tech. Conta também com piso porcelanato nas áreas da cozinha e banheiro, e piso laminado no ambiente do quarto/sala. Por fim, ele já vem equipado com aquecimento de água central, previsão para ar condicionado e um caixilho de tamanho diferenciado, que compreende basicamente o tamanho da parede em que se encontra, visando garantir 0 conforto térmico e luminotécnico.

Saindo da unidade e olhando o conjunto edificado, é possível verificar que foram criadas áreas compartilhadas para suprir as necessidades que 0 apartamento não supre. Além das áreas já compartilhadas em condomínios tradicionais, tal como lobby e academia, no VN Nova Higienópolis também espaços como cozinha compartilhada, cooworking, cinebar, bike sharing, lavanderia coletiva e até mesmo o compartilhamento de utensílios como ferramentas (Figura 06). 

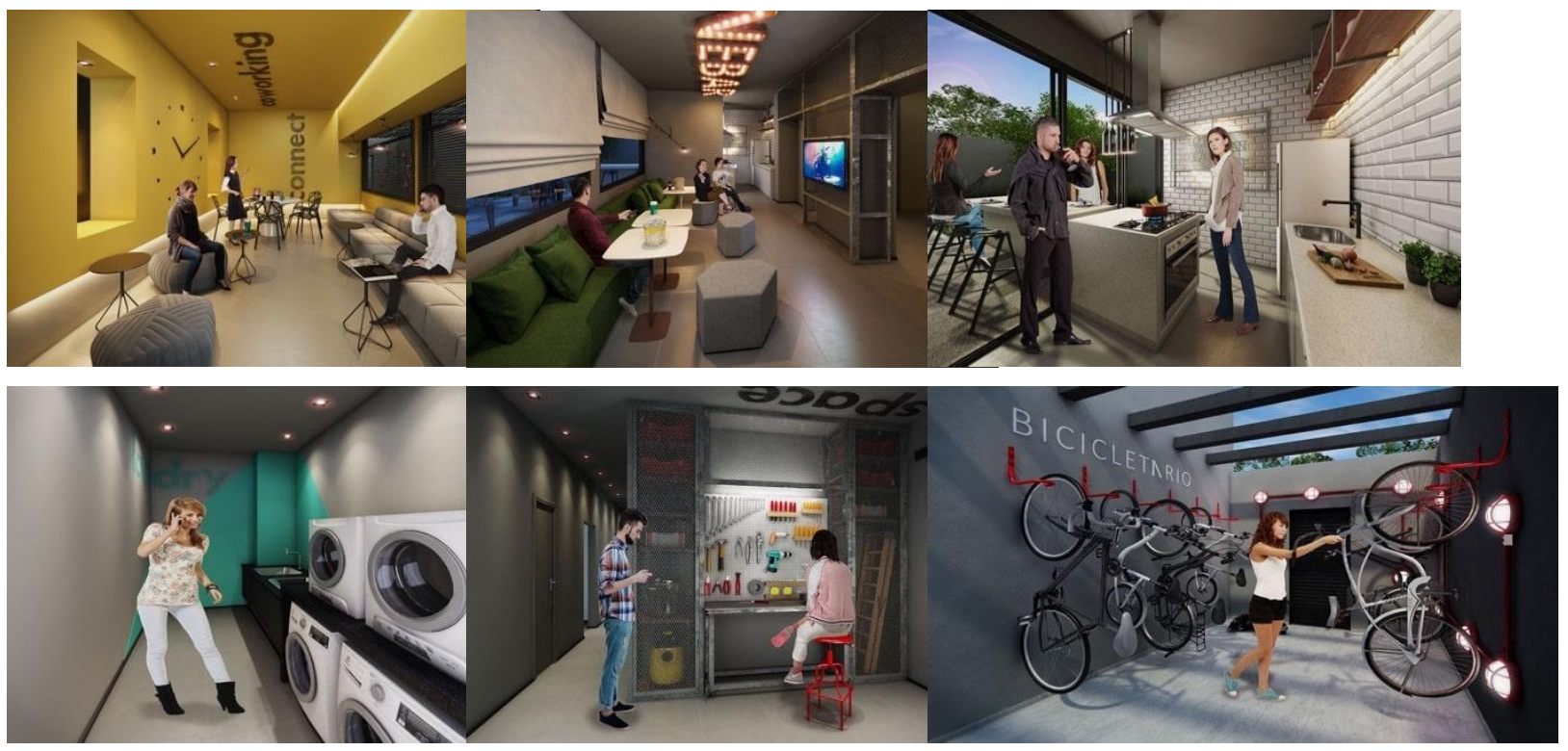

Figura 6 - Áreas comuns do edifício VN Nova Higienópolis respectivamente: cooworking, cinebar, cozinha compartilhada, lavanderia coletiva, utensílios compartilhados e bike sharing.

Fonte: Site da construtora e incorporadora VITACON.

\subsection{Estudo 2: MOOV Estação Brás, São Paulo - SP}

Apesar de possuir quase o dobro da área do estudo anterior, o MOOV Estação Brás é ainda considerado um microapartamento por possuir uma metragem quadrada menor que a média dos apartamentos tradicionais. Este apartamento de $19 \mathrm{~m}^{2}$ projetado, incorporado e construído pela Construtora Gafisa faz parte de uma linha lançada pela construtora chamada MOOV, que até o momento conta com 6 lançamentos. A linha MOOV tem como característica o viver a cidade, o andar a pé, o uso do transporte público e bicicletas para fugir do trânsito da cidade, e próximo a metrôs, faculdades e parques.

Localizado na rua Piratininga, Centro de São Paulo, o empreendimento fica a aproximadamente 200 metros da Estação Brás, e próximo do hospital Sancta Maggiore, Univeridade Anhembi Morumbi, Shopping Tatuapé e Sesc Belenzinho.

Com localização privilegiada, este edifício segue a linha MOOV. Perto de transportes públicos, permitindo fácil locomoção dos usuários, dispensando-os de enfrentar o trânsito da cidade; próximo de centros culturais, como o Sesc Belenzinho, possibilitando que o morador vivencie a cidade e seus programas culturais. Sua proximidade com a Universidade Anhembi Morumbi é também relevante, pois atinge parte do público alvo que a construtora busca alcançar, os estudantes.

Além dos estudantes, a linha MOOV tem como público alvo pessoas solteiras e recém-casados iniciando uma nova família. Semelhante ao caso anterior, com sua proximidade com o hospital Sancta Maggiore, o edifício também é um bom local para profissionais da saúde, onde podem descansar entre plantões. E além destes usuários que usam o espaço caracterizado como morar eventual, devido sua localização em um dos principais centros de compras de São Paulo, o MOOV também tem como público alvo os lojistas que vão a cidade fazer compras, caracterizando um público eventual. 
Devido sua área reduzida, percebe-se o uso da descompartimentação do espaço, resultando na economia de espaço desperdiçado com paredes e na sensação de amplitude do ambiente. Porém, a área reduzida resulta na necessidade do microapartamento de possuir um planejamento do espaço interior, sendo novamente importante a presença de um design de interiores para mais uma vez garantir conforto ao usuário. Neste caso é ideal que se faça uso de móveis planejados, sob medidas. A própria incorporadora em seu material de marketing divulgou duas propostas de configurações da planta baixa do apartamento, sugerindo a necessidade de móveis versáteis e flexíveis (Figura 07).

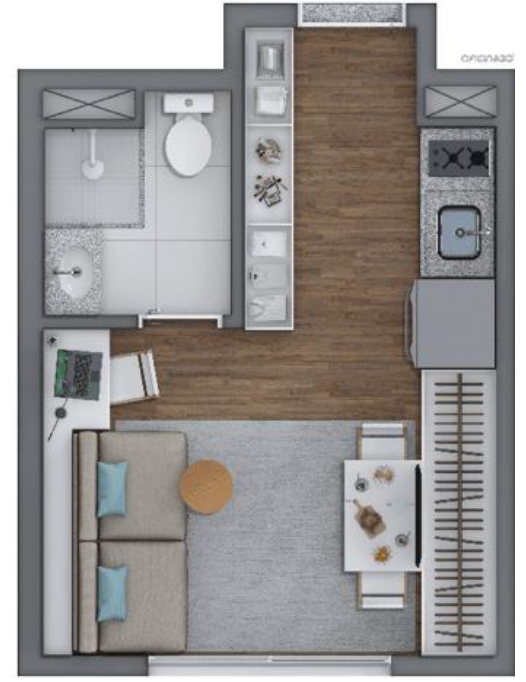

(a)

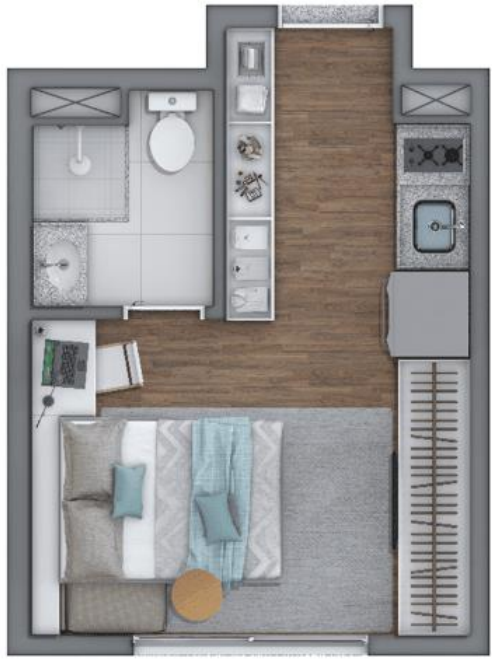

(b)

Figura 7 - Planta baixa. (a) Opção sofá. (b) Opção cama.

Fonte: Material de venda do empreendimento divulgado pela Gafisa.

Como é possível observar a partir da Figura 07, o sofá se transforma em cama, além disso os arquitetos sugerem a presença de uma mesa móvel para uso quando necessário. Ainda no material de divulgação, nas imagens 3D podese observar o mobiliário proposto especificamente para este ambiente. A mesa por exemplo se encaixa em um nicho quando não utilizada e as cadeiras são dobráveis, guardando-as no armário (Figuras 08 e 09). Existe ainda a proposta de um armário que desdobra e vira tábua de passar e calceiro.

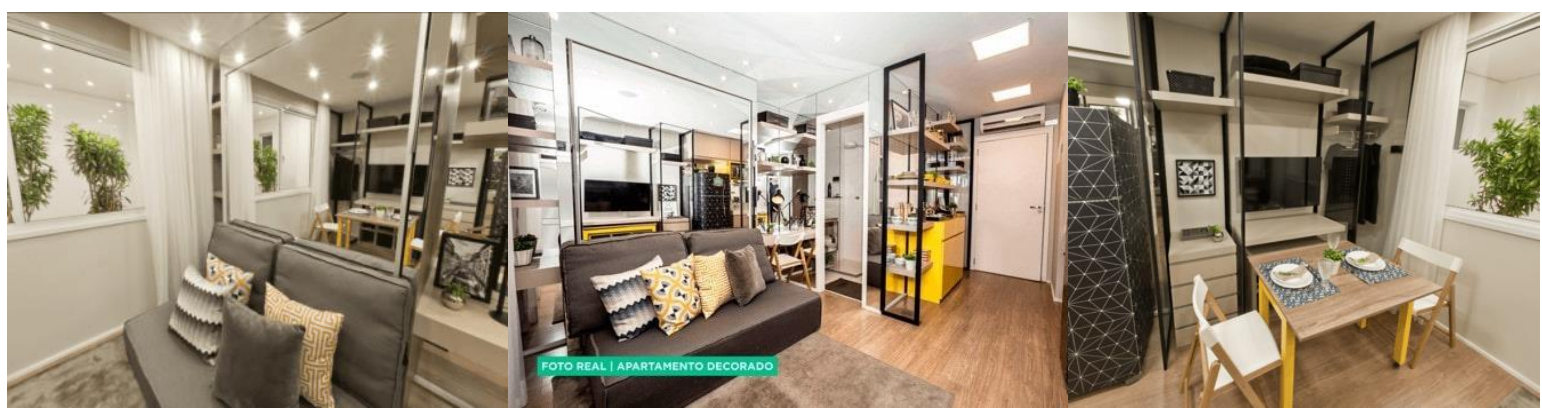

Figura 8 - Apartamento decorado com a opção "dia" proposta pela construtora: sofá e mesa de refeição aberta.

Fonte: Material de venda do empreendimento divulgado pela Gafisa. 


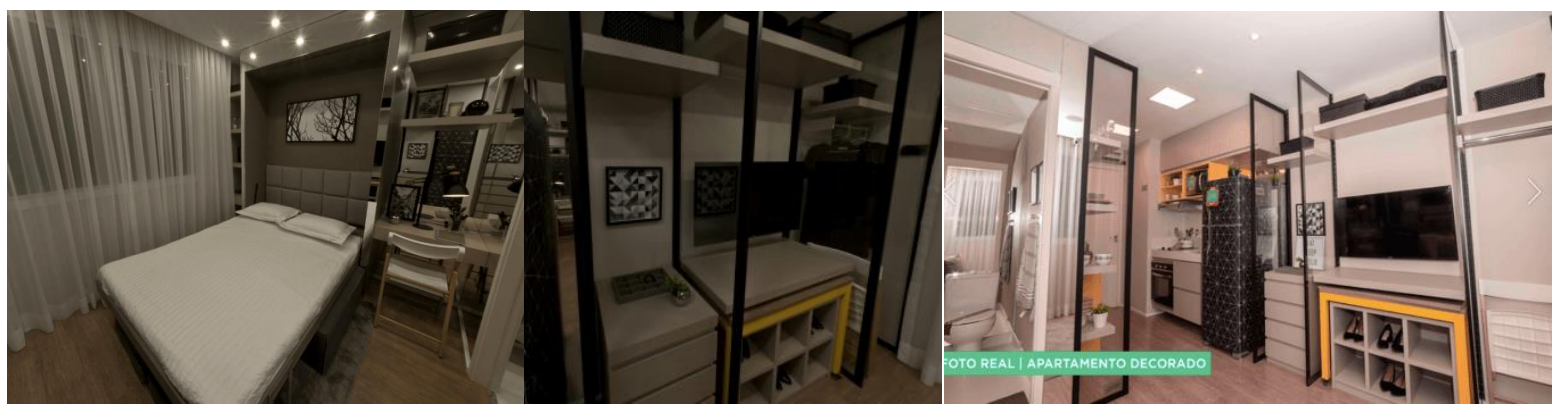

Figura 9 - Apartamento decorado com a opção "noite" proposta pela construtora: sofá aberto transformando-se em cama, mesa de refeição fechada e cadeiras guardadas no armário.

Fonte: Material de venda do empreendimento divulgado pela Gafisa.

Como no caso anterior, o MOOV Estação Brás é um apartamento de alto padrão, focado em um público seleto. Dessa maneira seus acabamentos são de alta qualidade, pensados em agradar seu usuário. O apartamento já conta com forro de gesso e pisos laminados, com exceção do banheiro que possui porcelanato. A cozinha e banheiro são entregues com bancadas em granito instaladas e por fim, possui infra-estrutura completa para a instalação de arcondicionado.

Analisando o empreendimento como um todo todo, inclusive as áreas comuns entre condôminos, observa-se que o edifício possui uma grande variedade de serviços para seus usuários, suprindo eventuais necessidades que o espaço reduzido do apartamento venha a causar. Além dos espaços coletivos tradicionas, tais como churrasqueira e piscina, o empreendimento possui também o espaço MOOV (uma sala de jogos e TV), lavanderia e lounge coletivo, espaço compartilhado de ferramentas e espaço funcional (Figura 10).

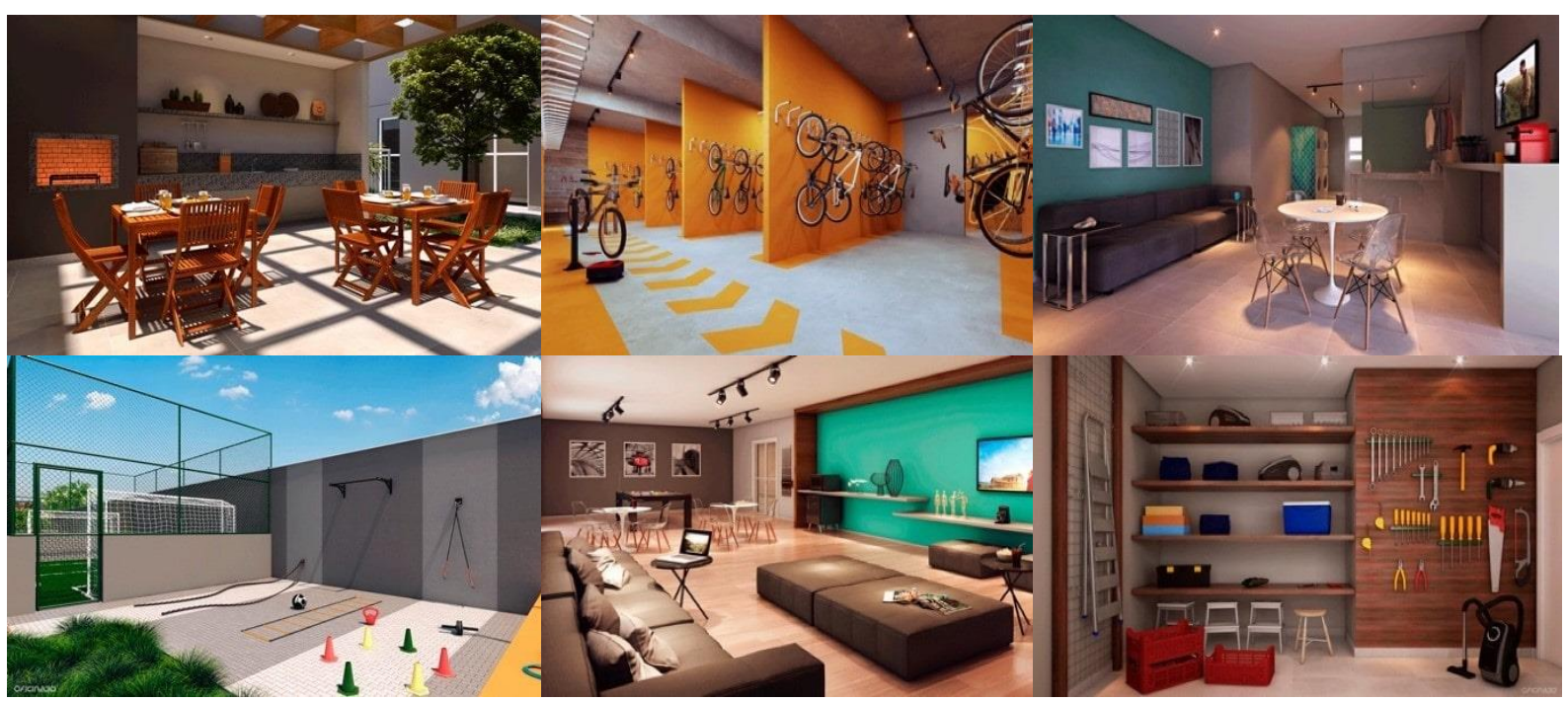

Figura 10 - Áreas comuns do MOOV Estação Brás respectivamente: churrasqueira,

bicicletário, lavanderia compartilhada, espaço funcional, espaço MOOV, espaço compartilhado de ferramentas.

Fonte: Material de venda do empreendimento divulgado pela Gafisa.

Após análises dos apartamentos foi possível encontrar divergências e, principalmente, pontos semelhantes entre si. Pode-se afirmar que os empreendimentos são bem parecidos, possuindo como diferença apenas a metragem quadrada, visto que o MOOV Estação Brás tem $9 \mathrm{~m}^{2}$ a mais que o VN Nova Higienópolis. 
Apesar de não possuirem as mesmas áreas comuns, a essência é a mesma, garantir o lazer dos condominos. Em ambos os casos as áreas servem também como uma extenção do apartamento, dando suporte as atividades que foram excluídas dos mesmos, caso da lavanderia, e para as atividades que o apartamento não comporta, como recepção de amigos.

Os dois apartamentos estudados tiveram seus programas tradicionais enxugados até chegarem a tipologia básica e comum que consiste em um ambiente único sem divisórias, que contêm um quarto/sala, cozinha/corredor e banheiro. Todos os outros programas tradicionais foram delegados para 0 ambiente comum dos moradores.

Apesar de não ser a mesma localização, são semelhantes tanto por estarem na região central da Capital Paulista, como por estarem próximas de transportes públicos, hospitais e universidades. Inclusive, são consequências do público que as incorporadoras pretendem atingir.

Ademais, os microapartamentos do VN Nova Higienópolis e do MOOV Estação Brás, afirmam a necessidade de um designer de interiores desde o momento de sua concepção, como é demonstrado nos materiais publicitários dos empreendimentos. Nos dois casos observa-se a necessidade de móveis planejados e flexíveis, com cama que se transforma em sofá, mesas que se encaixam em nichos, entre outras soluções criativas e interessantes que seus materiais de divulgação sugerem.

\section{CONCLUSÕES}

Descompartimentação dos espaços é base para a realização desses microapartamentos. Pois a retirada das paredes resulta na união dos espaços, o que por sua vez, permite a sensação de amplitude dos apartamentos, além dos usos simultâneos do espaço, tal como quarto e sala.

Junto a isso, a necessidade que o microapartamento tem em ter um bom planejamento e designe. Isto porque, com suas metragens mínimas, os móveis tradicionais não atendem as necessidades, seja pelas grandes dimenssões ou pela rigidez de uso. O planejamento dos espaços auxiliará no conforto do usuário e a organização do ambiente, evitando que o apartamento se torne uma morada caótica como as registradas por Benny Lam.

Por fim, pode-se concluir a partir dos resultados, que apesar dos microapartamentos serem um produto que surge com força no mercado imobiliário, o principal motivo que justifica seu lançamento é o atual contexto, caracterizado pelo morar eventual dos usuários, seja pelo de descanso entre plantões, aulas e trabalho, ou seja pelo viver a cidade intensamente.

\section{REFERÊNCIAS}

BRITTO, F. Clássicos da arquitetura: Nakagin Capsule Tower / Kisho Kurokawa.

Disponível em: <https://www.archdaily.com.br/br/01-36195/classicos-daarquitetura-nakagin-capsule-tower-kisho-kurokawa>. Acessado em: $01 / 11 / 2018$.

CARNEIRO, L.; VALENTE, G.; BATISTA, H.G. Exemplos de plantas de apartamentos de dois quartos ao longo das décadas. Disponível em: $<$ https://infograficos.oglobo.globo.com/economia/exemplos-de-plantas-deapartamentos-de-dois-quartos-ao-longo-das-decadas.html> Acessado em: 22/09/2018. 
GROAT, L.; WANG, D. Architectural research methods. Nova lorque: John Wiley \& Sons, 2002.

LAM, B. Boxed in: life inside the "coffin cubicles" of Hong Kongs - in pictures.

Disponível em:

<https://www.theguardian.com/cities/gallery/2017/jun/07/boxed-life-insidehong-kong-coffin-cubicles-cage-homes-in-pictures>. Acessado em: 06/10/2018.

TRAMONTANO, M. Habitações, metrópoles e modos de vida. Por uma reflexão sobre o espaço doméstico contemporâneo. $3^{\circ}$ Prêmio Jovens Arquitetos, categoria "Ensaio Crítico". Sao Paulo: Instituto dos Arquitetos do Brasil / Museu da Casa Brasileira, 1997. 210mm x 297mm. 10p. llustr. Disponível em: <http://www.nomads.usp.br/site/livraria/livraria.html>. Acessado em: $01 / 11 / 2018$.

RACY, S. Vitacon lança novo empreeendimento com apartamentos de $10 \mathrm{~m}^{2}$. Disponível em: <https://vitacon.com.br/new/blog/vitacon-lanca-novoempreendimento-com-apartamentos-de-10m\%C2\%B2/>. Acessado em: 26/10/2018.

ROLNIK, R. Apartamentos de 10m²: mínimo necessário ou lucro máximo? Disponível em: <https://raquelrolnik.wordpress.com/2017/08/21/apartamentosde-10-m\%C2\%B2-minimo-necessario-ou-lucro-maximo/amp/>. Acessado em: $13 / 11 / 2018$. 